\title{
Role of BRCA2 mutation status on overall survival among breast
} cancer patients from Sardinia

\author{
Mario Budroni*1, Rosaria Cesaraccio ${ }^{1}$, Vincenzo Coviello², Ornelia Sechi ${ }^{1}$, \\ Daniela Pirino ${ }^{1}$, Antonio Cossu ${ }^{3}$, Francesco Tanda ${ }^{3}$, Marina Pisano ${ }^{4}$, \\ Grazia Palomba ${ }^{4}$ and Giuseppe Palmieri ${ }^{4}$
}

\author{
Address: ${ }^{1}$ Registro Tumori di Sassari, ASL 1, Sassari, Italy, ${ }^{2}$ Dipartimento Prevenzione, ASL BA1, Bari, Italy, ${ }^{3}$ Istituto di Anatomia Patologica, \\ Università di Sassari, Sassari, Italy and ${ }^{4}$ Unità Genetica dei Tumori, Istituto di Chimica Biomolecolare-CNR, Sassari, Italy \\ Email: Mario Budroni* - mariobudroni@tiscali.it; Rosaria Cesaraccio - rosariacesaraccio@tiscali.it; Vincenzo Coviello - enzo.coviello@alice.it; \\ Ornelia Sechi - orneliasechi@tiscali.it; Daniela Pirino - danielapirino@tiscali.it; Antonio Cossu - cossu@uniss.it; \\ Francesco Tanda - tandaf@uniss.it; Marina Pisano - marina.pisano@icb.cnr.it; Grazia Palomba - graziap68@yahoo.it; \\ Giuseppe Palmieri - gpalmieri@yahoo.com \\ * Corresponding author
}

Published: 20 February 2009

BMC Cancer 2009, 9:62 doi:10.1 I86/147|-2407-9-62

This article is available from: http://www.biomedcentral.com/I47/-2407/9/62

(c) 2009 Budroni et al; licensee BioMed Central Ltd.

This is an Open Access article distributed under the terms of the Creative Commons Attribution License (http://creativecommons.org/licenses/by/2.0), which permits unrestricted use, distribution, and reproduction in any medium, provided the original work is properly cited.
Received: 18 July 2008

Accepted: 20 February 2009

\begin{abstract}
Background: Germline mutations in BRCAI or BRCA2 genes have been demonstrated to increase the risk of developing breast cancer. Conversely, the impact of BRCA mutations on prognosis and survival of breast cancer patients is still debated. In this study, we investigated the role of such mutations on breast cancer-specific survival among patients from North Sardinia.
\end{abstract}

Methods: Among incident cases during the period 1997-2002, a total of $5 / 2$ breast cancer patients gave their consent to undergo BRCA mutation screening by DHPLC analysis and automated DNA sequencing. The Hakulinen, Kaplan-Meier, and Cox regression methods were used for both relative survival assessment and statistical analysis.

Results: In our series, patients carrying a germline mutation in coding regions and splice boundaries of $B R C A I$ and $B R C A 2$ genes were $48 / 512$ (9\%). Effect on overall survival was evaluated taking into consideration BRCA2 carriers, who represented the vast majority $(44 / 48 ; 92 \%)$ of mutation-positive patients. A lower breast cancer-specific overall survival rate was observed in BRCA2 mutation carriers after the first two years from diagnosis. However, survival rates were similar in both groups after five years from diagnosis. No significant difference was found for age of onset, disease stage, and primary tumour histopathology between the two subsets.

Conclusion: In Sardinian breast cancer population, BRCA2 was the most affected gene and the effects of BRCA2 germline mutations on patients' survival were demonstrated to vary within the first two years from diagnosis. After a longer follow-up observation, breast cancer-specific rates of death were instead similar for BRCA2 mutation carriers and non-carriers. 


\section{Background}

The breast cancer is a complex disease with high biological heterogeneity and wide spectrum of responsiveness to different treatments. The well-established prognostic factors currently used into the management of patients with breast carcinoma include the disease stage (which takes into account tumour size, axillary lymph node involvement, and distant tumour dissemination) as well as the histological type, the degree of differentiation (tumour grade), the proliferation index, and the receptor status [estrogen receptor (ER), progesterone receptor (PR), and, recently, HER2] of the primary tumours [1]. Among them, the expression levels of hormone receptors seem to better predict the breast cancer response to different therapeutic strategies. More in general, the assessment of some molecular mechanisms responsible for the mammary tumourigenesis and studies on molecular profiling allowed to identify several biomarkers which may be helpful to pathologically classify breast cancer lesions into subtypes with different prognostic and clinico-pathologic behaviours $[2,3]$.

Mutations in the BRCA1 and BRCA2 tumour suppressor genes have been associated with the breast cancer risk among families with strong recurrence of the disease [49]. Vast majority of studies has shown a highly increased risk of developing breast cancer in BRCA1 or BRCA2 mutation carriers [4-7] with also a greater incidence of a second contra-lateral tumour $[4,5,10]$. However, majority of breast cancers occur sporadically in individuals with little or no family history, for whom no clear role of the mutations in BRCA genes has emerged. Overall, BRCA mutations are responsible for $30-60 \%$ of the hereditary cases and have a prevalence of about $5 \%$ in the general population and about $25 \%$ in the families with history of breast cancer [9].

Analogously, several studies have investigated the possible effects of BRCA mutations on clinical and pathologic characteristics of breast cancer as well as on prognosis and survival rates of the patients, but the results were inconclusive. Some of these studies have demonstrated that BRCA1 mutation carriers develop cancer with a high proliferation index and low expression of estrogen receptors $[11,12]$. Moreover, a higher proliferation index has been reported in all breast cancer sporadic cases carrying a BRCA germline mutation (regardless of the gene involved) in comparison to the patients with wild-type $B R C A$ [13-15]. Conversely, other authors observed no difference in histological tumour features among BRCA2positive familial cases and sporadic cases [16]. Regarding the relationship with the survival, BRCA1 mutation carriers showed either a poor prognosis in patients with negative lymph nodes [17] or a worse outcome in comparison with BRCA2-positive cases $[18,19]$. Other investigators did not find any significant survival difference in BRCA mutation carriers compared with non-carrier cases $[20,21]$; moreover, breast cancer specific mortality rates have been found similar for BRCA mutation carriers and non-carriers in Jewish population [22]. Nevertheless, a better assessment of the role on survival and prognosis could be also important for women with a BRCA mutation who face a decision between preventive surgery and intensive surveillance.

In Sardinia, whose population is genetically homogeneous due to the fact that it is relatively isolated and with high rate of inbreeding, the contribution of BRCA mutations to the population incidence of breast cancer has been evaluated by our group in recent past years [23-25]. Three deleterious BRCA germline mutations have been observed in about $15 \%$ families and in about 3\% nonfamilial breast cancer patients from North Sardinia (BRCA2 mutations were the most prevalent BRCA sequence variations and a single variant, BRCA28765delAG, was the most recurrent mutation with a founder effect in our population) [23-25]. In North Sardinia, breast cancer represents the principal death-causing malignancy, with an incidence rate quite comparable with that observed in Western countries (standardized rate, 95 per 100.000 inhabitants per year); the median age of onset for breast cancer among Sardinian women is 65 years [26]. Based on the existence of an official cancer registry, which has recorded all malignancies diagnosed into the population of the province of Sassari from 1992 to 2003 [26], the objective of the present study was to investigate the relationship between the occurrence of BRCA mutations and the main standardized prognostic factors as well as the overall survival rates among breast cancer patients from North Sardinia. Specifically, we compared survival rates between BRCA2 mutation carriers and noncarriers while adjusting for demographic and clinicallyrecognized prognostic factors in a homogenous group of Sardinian breast cancer patients.

\section{Methods \\ Patients' selection}

Among 1,835 incident cases during the period 19972002 [with 140 (8\%) tumour-specific deaths], we selected all consecutive patients with histologically-proven diagnosis of malignant breast cancer (regardless of factors which may influence prognosis: age, family history, disease stage, or type of treatment). Among them, 512 patients gave their consent to undergo genetic analysis for detection of BRCA mutations on germline DNA from peripheral blood. For such cases, the collected information included the disease stage at diagnosis, the expression levels of estrogen and progesterone receptors, and the occurrence of a second cancer. All information have been verified through analysis of the hospital records; all cancer diagnoses were confirmed by pathology reports. 
The study was reviewed and approved by the ethical review boards of both Institutions (University of Sassari and A.S.L.1 of Sassari).

\section{Mutation screening}

For the BRCA1 and BRCA2 genetic testing, all patients were informed about the aims and limits of the mutation analysis and blood samples were collected after obtaining a patient's written consent (in any case, documentation of counselling was carefully evaluated prior to genetic testing). As previously described $[23,24]$, genomic DNA samples were screened for mutations in BRCA1 and BRCA2 genes by a sequential combination of denaturing highperformance liquid chromatography (DHPLC) analysis and sequencing approach using an automated fluorescence-cycle sequencer (ABIPRISM 3100, Applied Biosystems, Foster City, CA).

\section{Statistical analysis}

The following variables and categories were defined and included in our analyses: pathological primary tumor size (pT), pathological nodal status $(\mathrm{pN})$, presence of distant metastases $(\mathrm{M})$, estrogen and progesteron receptor (ER and $\mathrm{PR}$, respectively) status, age at diagnosis, and overall survival (calculated starting from the time of diagnosis to the date of death or to the end of our follow-up observation on December 31, 2004). Receptor status was not known in a fraction (about 30\%) of the patients included into the study.

The general mortality data were provided from official regional sources, and in some cases were drawn from the municipality rosters. The death probability was calculated on the mortality rate basis and expressed as the probability that an individual has, at beginning of the age class considered, to die before going to the next age class. The formula from life-table that assume a constant mortality rate within a given period was applied [27]. In this case, the age class was equal to one year, as required by the Hakulinen method for calculation of relative survival [28].

The five-year relative survival figures were also computed following the Hakulinen method [28]; the 95\% confidence limits were calculated using the "eurocare " confidence interval algorithm [29]. For the comparison of survival probabilities within the various subgroups, the cumulative relative survival adjusted for age was estimated using the technique proposed by Brenner and colleagues [29].

The role of familiarity and BRCA status as genetic marker in cause-specific survival was investigated by KaplanMeier and Cox regression methods. All tests were computed by Stata Software.

\section{Results}

Among the 512 breast cancer patients who gave their consent to participate to the study, $103(20 \%)$ had a family history of breast cancer. Cases were classified as familial when at least three affected members (considering firstand second-degree relatives) were diagnosed with breast cancer.

Mutation analysis for all coding regions and splice boundaries of BRCA1 and BRCA2 genes was performed as previously described [24]. Briefly, germline DNA from breast cancer patients was screened by DHPLC analysis; all PCR products presenting an abnormal denaturing profile in comparison to the normal controls were sequenced using an automated approach. Taking into consideration the 103 familial cases, $2(2 \%)$ and $20(19 \%)$ presented a germline mutation in BRCA1 and BRCA2 genes, respectively. Among the remaining 409 patients classified as sporadic cases, $2(0.5 \%)$ and $24(6 \%)$ were found to carry BRCA1 and BRCA2 mutations, respectively. Overall, patients carrying a BRCA mutation were $48 / 512(9 \%)$. In particular, BRCA1 mutations were detected in only $4 / 48$ $(8 \%)$ carriers, while BRCA2 mutations were identified in vast majority of them $(44 / 48 ; 92 \%)$, with the BRCA28765delAG variant acting as a founder mutation [23-25]. Taking into account such a high preponderance of germline mutations, only BRCA2-positive cases were considered for statistical correlations in our series.

The age of breast cancer onset was evaluated on the basis of the mutation status; $23 / 44$ (52\%) BRCA2 mutation positive and 188/464 (41\%) BRCA2 mutation negative patients were 50 years or younger at the time of diagnosis (Table 1). Although the average age at diagnosis was younger in patients carrying BRCA2 mutations [23/44 $(52 \%) \leq 50$ years $v$ s. $21 / 44(48 \%)>50$ years] than in cases with no detectable mutation $[188 / 464(41 \%) \leq 50$ years vs. $276 / 464(59 \%)>50$ years], such a difference was not statistically significant. Using Pearson's Chi-Squared test, the occurrence of a BRCA2 mutation was evaluated for association with several pathological parameters: $\mathrm{pT}, \mathrm{pN}$, $\mathrm{M}$, or, when available, ER and PR. As shown in Table 2, distribution of BRCA2 mutation carriers and non-carriers was quite identical in the different subsets of patients according to such pathological parameters (thus, no statistically significant correlation was observed - not shown).

Taking into consideration the primary tumour morphology, 348 (68\%) ductal carcinomas, 62 (12\%) lobular carcinomas, and $102(20 \%)$ other histological types were registered. The BRCA2 mutations were more prevalent in lobular $(7 / 62 ; 11 \%)$ than in ductal carcinomas $(20 / 348$; $6 \%)$; again, differences were not statistically significant. 
Table I: Distribution of patients according to BRCA2 mutation status and age of onset

\begin{tabular}{cccc}
\hline Age Class & BRCA2 mutation negative & BRCA2 mutation positive & Total \\
\hline 20 & 1 & 1 & 1 \\
25 & 2 & 2 & 3 \\
30 & 21 & 3 & 23 \\
35 & 27 & 7 & 30 \\
40 & 38 & 6 & 45 \\
45 & 54 & 4 & 60 \\
50 & 45 & 8 & 49 \\
55 & 57 & 3 & 50 \\
60 & 47 & 5 & 55 \\
65 & 50 & 1 & 57 \\
70 & 56 & 2 & 38 \\
80 & 36 & 1 & 22 \\
85 & 21 & 1 & 10 \\
\hline
\end{tabular}

The five-year survival rate was $81 \%(80 \%$, adjusted by age) among BRCA2 mutation carriers and 91\% (92\%, adjusted by age) among patients negative for BRCA2 mutations. Overall, the five-year relative survival rate for breast cancer cases from our series was $85 \%$. Evaluation of the overall survival curves using the Kaplan-Meier method indicated that patients carrying BRCA2 mutations presented a lower breast cancer-specific survival in comparison with those resulted negative for BRCA2 mutations, within the first two years from diagnosis (Figure 1). Considering the entire observation period of five years from diagnosis, the survival curves tended to merge with no sig-

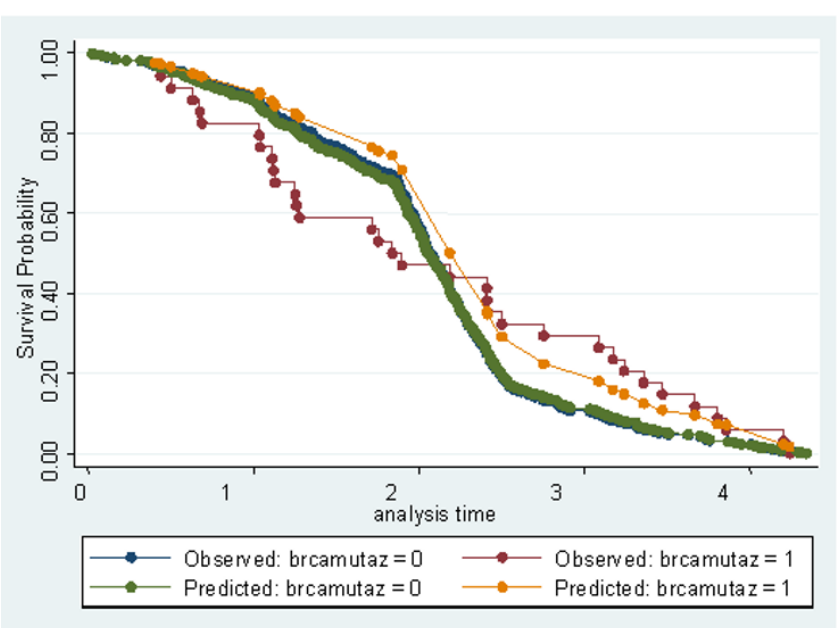

Figure I

Overall survival curves based on the Kaplan-Meier method. Comparison between observed and predicted survival data for each subset of patients (with or without BRCA2 mutations) is reported. nificant difference in outcome between the two groups (Figure 1). Furthermore, no difference in survival among familial and sporadic BRCA2 mutated cases was observed (not shown). As estimated by Cox regression analysis, the hazard ratio of patients positive for BRCA2 mutations was found to be 0.7 (95\% CI, 0.46-1.37), after adjustment by age (Figure 2), and about 0.8 (95\% CI, 0.48-1.62), after adjustment by disease stage (Figure 3 ). Hazard ratios were quite identical for both subsets when adjusted for tumour grade $(0.82 ; 95 \% \mathrm{CI}, 0.53-0.98)$ and receptor status (0.85; 95\% CI, 0.64-0.97) (not shown).

Finally, multivariate Cox regression analysis was performed considering all variables ( $\mathrm{pT}, \mathrm{pN}, \mathrm{M}, \mathrm{ER}, \mathrm{PR}$, and BRCA2 mutations). The presence of metastases was the only parameter with a significant impact on prognosis ( $p$

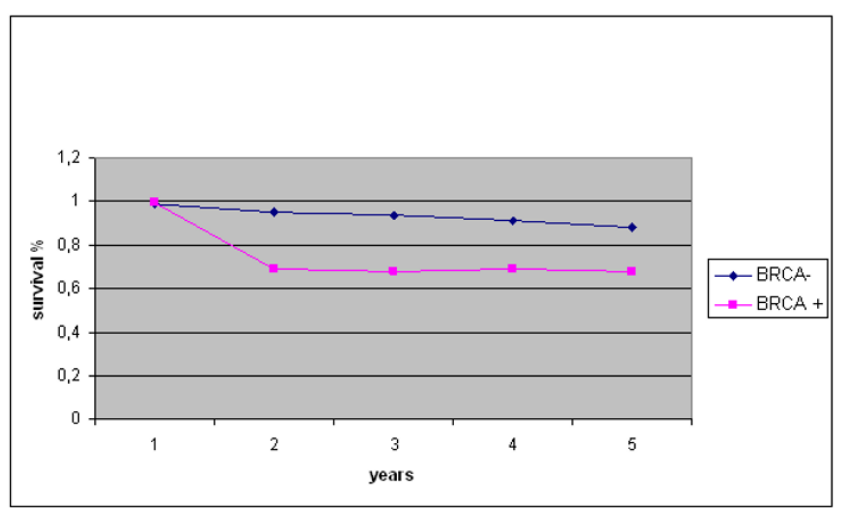

Figure 2

Relative five-year survival for breast cancer patients with or without BRCA2 mutations (BRCA+/-), adjusted by age according to Brenner. 
A

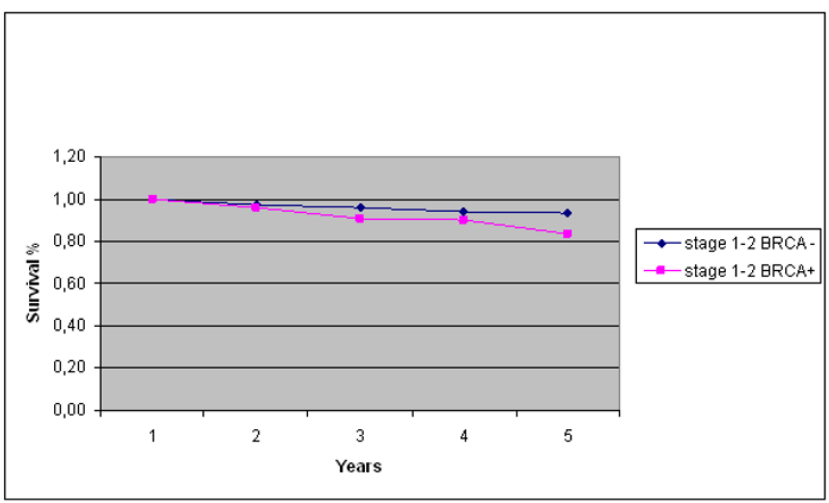

B

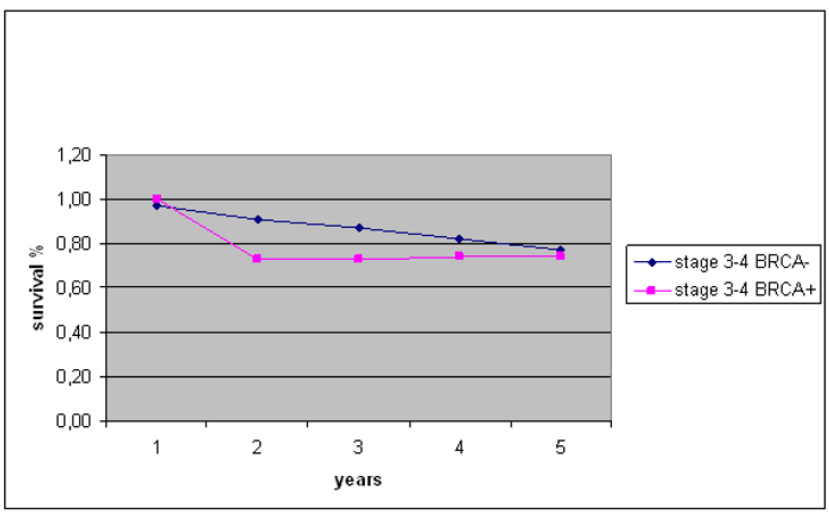

Figure 3

Relative five-year survival for breast cancer patients according to (A) localized disease (stage I-2) or (B) metastatic disease (stage 3-4), and presence or absence of BRCA2 mutations (BRCA+/-).

$<0.001$; hazard ratio, 8.939; 95\% CI, 4.68-17.1). However, such a prognostic factor was not able to exert a confounding effect on mutation-based survival curves due to the low number of patients with distant metastases (33/ $508 ; 6 \%)$, who even showed a similar prevalence of BRCA2 mutation-negative $(30 / 464 ; 6 \%)$ and mutationpositive $(3 / 44 ; 7 \%)$ cases (see Table 2$)$. No other association between BRCA2 mutation status and overall survival was observed for the remaining variables.

\section{Discussion and conclusion}

Breast cancers carrying BRCA1 or BRCA2 germline mutations often occur in younger women as well as present a high tumour grade and/or lack of expression of estrogen/ progesterone receptors (mostly, among BRCA1-positive tumours) [11-16,30-32]. Although these features have been associated with a poor prognosis, the relationship between the occurrence of a BRCA1 or BRCA2 mutation
Table 2: Distribution of BRCA2 cases according to the TNM and receptor status

\begin{tabular}{|c|c|c|c|}
\hline \multirow[b]{2}{*}{ BRCA2 mutation } & \multicolumn{3}{|c|}{ Primary tumour size } \\
\hline & TI-2 & T3-4 & Total \\
\hline Negative & $42191 \%$ & $439 \%$ & 464 \\
\hline Positive & $4193 \%$ & $37 \%$ & 44 \\
\hline \multirow[t]{2}{*}{ Total } & $46291 \%$ & $469 \%$ & 508 \\
\hline & \multicolumn{3}{|c|}{ Lymph node metastasis } \\
\hline BRCA2 mutation & Negative & Positive & Total \\
\hline Negative & $26357 \%$ & $20143 \%$ & 464 \\
\hline Positive & $2455 \%$ & $2045 \%$ & 44 \\
\hline \multirow[t]{2}{*}{ Total } & $28756 \%$ & $22144 \%$ & 508 \\
\hline & \multicolumn{3}{|c|}{ Distant metastasis } \\
\hline BRCA2 mutation & Absent & Present & Total \\
\hline Negative & $43494 \%$ & $306 \%$ & 464 \\
\hline Positive & $4193 \%$ & $37 \%$ & 44 \\
\hline \multirow[t]{2}{*}{ Total } & $47594 \%$ & $336 \%$ & 508 \\
\hline & \multicolumn{3}{|c|}{ Estrogen receptor } \\
\hline BRCA2 mutation & Negative & Positive & Total \\
\hline Negative & $9126 \%$ & $25774 \%$ & 348 \\
\hline Positive & $529 \%$ & $1271 \%$ & 17 \\
\hline \multirow[t]{2}{*}{ Total } & $9626 \%$ & $26974 \%$ & 365 \\
\hline & \multicolumn{3}{|c|}{ Progesterone receptor } \\
\hline BRCA2 mutation & Negative & Positive & Total \\
\hline Negative & $15044 \%$ & $18956 \%$ & 339 \\
\hline Positive & $646 \%$ & $754 \%$ & 13 \\
\hline Total & $15644 \%$ & $19656 \%$ & 352 \\
\hline
\end{tabular}

and the effect on overall survival is still controversial [1722,31,33-35].

In this study, we tried to clarify the role of BRCA mutations on the outcome of breast cancer patients from North Sardinia, where an official cancer registry is available [26]. In particular, we evaluated the 5-year survival rates among women who had received the diagnosis of breast cancer from 1997 to 2002 and gave their consent to undergo a BRCA genetic testing. Among the 508 analyzed patients, we assessed the breast cancer-specific survival rates for women with (44 cases; 9\%) or without (464 cases; $91 \%$ ) a BRCA2 germline mutation.

Using the Kaplan-Meier method, the survival rate of patients with a positive BRCA2 genetic test was lower than that of patients with negative genetic tests within the first two years after diagnosis in our series. However, the two survival curves tended to merge at the end of five years from diagnosis (see Figure 1). This trend may indeed account for the absence of significance of the Cox regression for BRCA2 status, due to the failure of proportionality of hazards (a situation in which calculation of a total hazard ratio with the Cox model is unsuitable). The rela- 
tive survival of the entire Sardinian series at five years from diagnosis is slightly below the average survival rate observed in breast cancer cases from the other Italian regions [17]; moreover, it always remains lower in the subset of BRCA2 mutation carriers than in that of BRCA2 mutation-negative patients, regardless the adjustments according to the different prognostic parameters in multivariate analysis (see Figures 2 and 3 ). Indeed, the relative survival seems to be worse in cases with positive BRCA2 genetic tests, even after adjustment for age of onset (which represents one of the factors with the greatest influence on cancer prognosis, according to the studies in other populations [34-36]). Although survival is also deeply influenced by disease stage at the time of diagnosis, we observed no significant difference between the two $B R C A 2$ subsets after stratification by stage.

Although our study has a number of limitations mainly due to the fact that we identified only a limited fraction $(44 / 508 ; 9 \%)$ of mutation carriers and, thus, the subgroup analyses relied on a small number of subjects, we can conclude that a prolonged follow-up observation seems to minimize the effect of the presence of $B R C A 2$ germline mutations on prognosis among breast cancer patients from Sardinian population.

Our findings are consistent with data recently reported in Israeli women of Ashkenazi Jewish ancestry (who present a high prevalence of hereditary breast cancer and BRCA founder mutations) [22] as well as in a Dutch series of BRCA1-associated breast carcinoma patients [37]. In both studies, the breast cancer-specific survivals for carriers and noncarriers of $B R C A$ mutations were similar, even considering a longer period of observation (ten years) from diagnosis [22,37]. On the basis of these results, one could speculate that additional factors may influence the prognosis in such patients.

Search for prognostic factors in breast cancer patients is still a challenge; several lifestyle and environmental risk factors for breast cancer are being investigated. For example, evidence have been recently found that an increase in body mass index is associated with a poorer prognosis in women receiving diagnosis of breast cancer [36]. Probably, further studies toward the comprehension of the underlying interactions between all genetic and environmental factors could really improve the classification of the different subsets of patients who would be expected to have better or worse prognosis as well as to be more or less likely to respond to specific therapeutic interventions.

\section{Competing interests}

The authors declare that they have no competing interests.

\section{Authors' contributions}

MB participated to the design of the study and performed statistical analyses. RC participated to analysis and interpretation of data. VC participated to statistical analysis. OS participated to analysis and interpretation of data. DP performed the data management. AC participated to patients' collection and performed some screening analyses. FT participated to patients' collection. MP participated to mutation analysis. GrP performed mutation screening. GiP conceived of the study and drafted the manuscript. All authors read and approved the final manuscript.

\section{Acknowledgements}

Authors are grateful to patients and families for their important contribution to this study. Work was funded by Regione Autonoma della Sardegna, Ricerca Finalizzata Ministero della Salute, Associazione Italiana Ricerca sul Cancro (AIRC), and Associazione UMANA Onlus.

\section{References}

I. Lønning PE: Breast cancer prognostication and prediction: are we making progress? Ann Oncol 2007, I 8(Suppl 8):viii3-7.

2. van't Veer LJ, Dai $H$, Vijver MJ van de, He YD, Hart AA, Mao M, Peterse HL, Kooy K van der, Marton MJ, Witteveen AT, Schreiber G], Kerkhoven RM, Roberts C, Linsley PS, Bernards R, Friend SH: Gene expression profiling predicts clinical outcome of breast cancer. Nature 2002, 415:530-536.

3. Jarzabek K, Koda M, Kozlowski L, Mittre H, Sulkowski S, Kottler ML, Wolczynski S: Distinct mRNA, protein expression patterns and distribution of oestrogen receptors alpha and beta in human primary breast cancer: correlation with proliferation marker Ki-67 and clinicopathological factors. Eur J Cancer 2005, 4I:2924-34.

4. Ford D, Easton DF, Bishop DT, Narod SA, Godgar DE: Risks of cancer in BRCAI-mutation carriers. Breast Cancer Linkage Consortium. Lancet 1994, 343:692-695.

5. Easton DF, Ford D, Bishop DT: Breast Cancer Linkage Consortium. Breast and ovarian cancer incidence in BRCAI-mutation carriers. Am J Hum Genet 1995, 56:265-27I.

6. Easton DF, Steele L, Fields P, Ormiston W, Averill D, Daly PA, McManus R, Neuhausen SL, Ford D, Wooster R, Cannon-Albright LA, Stratton MR, Goldgar DE: Cancer risks in two large breast cancer families linked to BRCA2 on chromosome $13 \mathrm{q} / 2-13$. Am J Hum Genet 1997, 6 I: 120-128.

7. Ford D, Easton DF, Stratton M, Narod S, Goldgar D, Devilee P, Bishop DT, Weber B, Lenoir G, Chang-Claude J, Sobol H, Teare MD, Struewing J, Arason A, Scherneck S, Peto J, Rebbeck TR, Tonin P, Neuhausen S, Barkardottir R, Eyfjord J, Lynch H, Ponder BA, Gayther SA, Zelada-Hedman M: Genetic heterogeneity and penetrance analysis of the BRCAI and BRCA2 genes in breast cancer families. The Breast Cancer Linkage Consortium. Am J Hum Genet 1998, 62:676-689.

8. Kirova YM, Stoppa-Lyonnet D, Savignoni A, Sigal-Zafrani B, Fabre N, Fourquet A: Institut Curie Breast Cancer Study Group. Risk of breast cancer recurrence and contralateral breast cancer in relation to BRCAI and BRCA2 mutation status following breast-conserving surgery and radiotherapy. Eur J Cancer 2005, 41:2304-II.

9. Dent R, Warner E: Screening for hereditary breast cancer. Semin Oncol 2007, 34:392-400.

10. Metcalfe KA, Lubinski J, Ghadirian P, Lynch H, Kim-Sing C, Friedman E, Foulkes WD, Domchek S, Ainsworth P, Isaacs C, Tung N, Gronwald J, Cummings S, Wagner T, Manoukian S, Møller P, Weitzel J, Sun P, Narod SA: Hereditary Breast Cancer Clinical Study Group. Predictors of contralateral prophylactic mastectomy in women with a BRCAI or BRCA2 mutation: the Hereditary Breast Cancer Clinical Study Group. J Clin Oncol 2008, 26:1093-7.

II. Adem C, Reynolds C, Soderberg CL, Slezak JM, McDonnell SK, Sebo TJ, Schaid DJ, Myers JL, Sellers TA, Hartmann LC, Jenkins RB: Pathologic characteristics of breast parenchyma in patients with 
hereditary breast carcinoma, including BRCAI and BRCA2 mutation carriers. Cancer 2003, 97:I-II.

12. Chappuis PO, Nethercot V, Foules WD: Clinico-pathological characteristics of BRCAI and BRCA2-related breast cancer. Semin Surg Oncol 2000, 18:287-295.

13. Honrado E, Benítez J, Palacios J: Histopathology of BRCAI- and BRCA2-associated breast cancer. Crit Rev Oncol Hematol 2006, 59:27-39.

14. Palacios J, Honrado E, Osorio A, Cazorla A, Sarrió D, Barroso A, Rodríguez S, Cigudosa JC, Diez O, Alonso C, Lerma E, Sánchez L, Rivas C, Benítez J: Immunohistochemical characteristics defined by tissue microarray of hereditary breast cancer not attributable to BRCAl or BRCA2 mutations: differences from breast carcinomas arising in BRCAI and BRCA2 mutation carriers. Clin Cancer Res 2003, 9:3606-36/4.

15. Lakhani SR, Jacquemier J, Sloane JP, Gusterson BA, Anderson TJ, Vijver MJ van de, Farid LM, Venter D, Antoniou A, Storfer-Isser A, Smyth E, Steel CM, Haites N, Scott RJ, Goldgar D, Neuhausen S, Daly PA, Ormiston W, McManus R, Scherneck S, Ponder BA, Ford D, Peto J, Stoppa-Lyonnet D, Bignon YJ, Struewing JP, Spurr NK, Bishop DT, Klijn JG, Devilee P, Cornelisse CJ, Lasset C, Lenoir G, Barkardottir RB, Egilsson V, Hamann U, Chang-Claude J, Sobol H, Weber B, Stratton MR, Easton DF: Multifactorial analysis of differences between sporadic breast cancers and cancers involving BRCAI and BRCA2 mutations. I Natl Cancer lnst 1998, 90: II38-1 I 45

16. The Breast Cancer Linkage Consortium. Pathology of familial breast cancer: differences between breast cancers in carriers of BRCAI or BRCA2 mutations and sporadic cases. Lancet 1997, 349:1505-1510.

17. Foulkes WD, Chappuis PO, Wong N, Brunet JS, Vesprini D, Rozen F, Yuan ZQ, Pollak MN, Kuperstein G, Narod SA, Begin LR: Primary node negative breast cancer in BRCAI mutation carriers has a poor outcome. Ann Oncol 2000, I I:307-I3.

18. Robson ME, Chappuis PO, Satagopan J, Wong N, Boyd J, Goffin JR, Hudis C, Roberge D, Norton L, Begin LR, Offit K, Foulkes WD: A combined analysis of outcome following breast cancer: differences in survival based on BRCA1/BRCA2 mutation status and administration of adjuvant treatment. Breast Cancer Res 2004, 6:

19. Stoppa-Lyonnet D, Ansquer Y, Dreyfus H, Gautier C, Gauthier-Villars M, Bourstyn E, Clough KB, Magdelenat H, Pouillart P, Vincent-Salomon A, Fourquet A, Asselain B: Familial invasive breast cancers: worse outcome related to BRCAI mutations. J Clin Oncol 2000, 18:4053-4059.

20. Johannsson OT, Ranstam J, Borg A, Olsson H: Survival of BRCAI breast and ovarian cancer patients: a population-based study from southern Sweden. J Clin Oncol 1998, 16:397-404.

21. Brekelmans CTM, Seynaeve C, Menke-Pluymers M: Survival and prognostic factors in BRCAI-associated breast cancer. Ann Oncol 2006, 17:39|-400.

22. Rennert G, Bisland-Naggan S, Barnett-Griness O: Clinical outcomes of breast cancer in carriers of BRCA1 and BRCA2 mutations. N Engl J Med 2007, 357: I I5-I 23.

23. Palmieri G, Palomba G, Cossu A, Pisano M, Dedola MF, Sarobba M, Farris A, Olmeo N, Contu A, Pasca A, Satta M, Persico I, Carboni A, Cossu-Rocca P, Contini M, Mangion J, Stratton MR, Tanda F: BRCAI and BRCA2 germline mutations in Sardinian breast cancer families and their implications for genetic counseling. Ann Oncol 2002, 13:1899-1907.

24. Palomba G, Pisano M, Cossu A, Budroni M, Dedola MF, Farris A, Contu A, Baldinu P, Tanda F, Palmieri G: Spectrum and prevalence of BRCAI and BRCA2 germline mutations in Sardinian breast cancer patients through a hospital-based screening. Cancer 2005, 104:1 I72-II79.

25. Palomba G, Cossu A, Friedman E, Budroni M, Farris A, Contu A, Pisano M, Baldinu P, Sini MC, Tanda F, Palmieri G: Origin and distribution of the BRCA2-8765delAG mutation in breast cancer. BMC Cancer 2007, 7:132.

26. Budroni M, Cesaraccio R, Pirino D, Sechi O, Oggiano M, Piras D, Sechi A, Cossu A, Palmieri G, Tanda F: Cancer incidence in Sassari Province (1998-2002). In Cancer Incidence in Five Continents, International Agency for Research on Cancer (IARC) Scientific Publications, No. I 60 Volume IX. Edited by: Curado MP, Edwards B, Shin HR, Storm H, Ferlay J, Heanue M, Boyle P. Lyon, IARC; 2007.
27. Hakulinen $\mathrm{T}$ : Cancer survival corrected for heterogeneity in patient withdrawal. Biometrics 1982, 38:933-942.

28. Verdecchia A, Capocaccia R, Hakulinen T: Methods of data analysis. In Survival of cancer patients in Europe. The EUROCARE study. IARC scientific publication 95 Edited by: Berrino F, SAnt M, Verdecchia A, Capocaccia R, Hakulinen T, Esteve J. Lyon International Agency for Research on Cancer; 1995.

29. Brenner $\mathrm{H}$, Hakulinen $\mathrm{T}$ : Age adjustment of cancer survival rates: methods, point estimates and standard errors. $\mathrm{Br} J \mathrm{Can}$ cer 2005, 93:372-5.

30. Mote PA, Leary JA, Avery KA, Sandelin K, Chenevix-Trench G, Kirk IA, Clarke CL: Germ-line mutations in BRCAI or BRCA2 in the normal breast are associated with altered expression of estrogen-responsive proteins and the predominance of progesterone receptor. Genes Chromosomes Cancer 2004, 39:236-48.

31. Veronesi A, de Giacomi C, Magri MD, Lombardi D, Zanetti M, Scuderi C, Dolcetti R, Viel A, Crivellari D, Bidoli E, Boiocchi M: Familial breast cancer: characteristics and outcome of BRCA I-2 positive and negative cases. BMC Cancer 2005, 5:70.

32. Musolino A, Bella MA, Bortesi B, Michiara M, Naldi N, Zanelli P, Capelletti M, Pezzuolo D, Camisa R, Savi M, Neri TM, Ardizzoni A: BRCA mutations, molecular markers, and clinical variables in early-onset breast cancer: a population-based study. Breast 2007, 16:280-92.

33. Eerola $H$, Vahteristo $P$, Sarantaus L: Survival of breast cancer patients in BRCAI, BRCA2, and non-BRCAI/2 breast cancer families: a relative survival analysis from Finland. Int J Cancer 200I, 93:368-72.

34. El-Tamer M, Russo D, Troxel A: Survival and recurrence after breast cancer in BRCAI/2 mutation carriers. Ann Surg Oncol 2004, I I:I57-64.

35. Moller P, Evans DG, Reis MM, Gregory H, Anderson E, Maehle L, Lalloo F, Howell A, Apold J, Clark N, Lucassen A, Steel CM: Surveillance for familial breast cancer: Differences in outcome according to BRCA mutation status. Int J Cancer 2007, I21:1017-1020.

36. Barnett GC, Shah M, Redman K, Easton DF, Ponder BAJ, Pharoah PDP: Risk factors for the incidence of breast cancer: do they affect survival from the disease? / Clin Oncol 2008, 26:33 |0-3316.

37. Brekelmans CT, Seynaeve C, Menke-Pluymers M, Brüggenwirth HT, Tilanus-Linthorst MM, Bartels CC, Kriege M, van Geel AN, Crepin CM, Blom JC, Meijers-Heijboer H, Klijn JG: Survival and prognostic factors in BRCAI-associated breast cancer. Ann Oncol 2006, 17:391-400.

\section{Pre-publication history}

The pre-publication history for this paper can be accessed here:

\section{http://www.biomedcentral.com/1471-2407/9/62/prepub}

Publish with Bio Med Central and every scientist can read your work free of charge

"BioMed Central will be the most significant development for disseminating the results of biomedical research in our lifetime. "

Sir Paul Nurse, Cancer Research UK

Your research papers will be:

- available free of charge to the entire biomedical community

- peer reviewed and published immediately upon acceptance

- cited in PubMed and archived on PubMed Central

- yours - you keep the copyright 